\title{
Activities of Japanese Multinationals with Productivity Heterogeneity*
}

\author{
Ryuhei Wakasugi $^{\dagger} \quad$ Ayumu Tanaka \\ Kyoto University RIETI
}

\begin{abstract}
Many studies have shown that a small number of firms with high productivity carry out FDI, but few studies have considered how country-specific attributes affect firm's choice of internationalization. This paper aims to investigate what factors vary the productivity-cutoff for overseas production and how these factors affect the activities of firms: the size of overseas production, the number of firms operating overseas production, the average domestic and overseas sales, and the relative share of overseas production to domestic production. The results of theoretical and empirical examination in this paper show that larger market size and shorter distance between two markets lower the productivity-cutoff for overseas production of Japanese firms, and that both larger market and shorter distance increase the number of firms operating overseas and the size of their overseas production.
\end{abstract}

\section{JEL classification: F10, F12, F20}

Keywords: Productivity-cutoff, heterogeneity, overseas production, market size, distance

\section{Introduction}

Production by overseas subsidiaries established with direct investment has become a central issue in current international trade studies. Melitz (2003) has shown that firms with high productivity tend to export. Helpman, Melitz, and Yeaple (2004) have shown that firms with high productivity tend to export and firms with higher productivity implement foreign direct investment (FDI) under a given market size and factor price. Following them, many theoretical and empirical studies have shown that only a small number of firms with high productivity are exporting and carrying out FDI ${ }^{1)}$. There are also a number of empirical studies on productivity's impact on

Received 7 September 2010; received in revised form 10 October 2010; accepted 25 October 2010.

* We sincerely dedicate this paper to the late Professor Kiyoshi Kojima. An earlier version of this paper was presented at the 2010 Spring Meeting of Japanese Economic Association (June 4, 2010) and at the seminars at Kyoto University and Keio University. We are grateful to Isao Kamata, participants of the meetings, and an anonymous referee of this journal for their valuable comments and suggestions which have improved the paper. Wakasugi thanks for the financial support of the Grant-in-Aid for Scientific Research No. (B) 20330046.

$\dagger$ Corresponding author. Institute of Economic Research, Kyoto University. Yoshida-honmachi, Sakyo-ku, Kyoto 606-8501, Japan. Fax: 81-(0) 75-753-7138, Email: wakasugi@kier.kyoto-u.ac.jp

1) Helpman (2006) is a comprehensive survey of literatures on the heterogeneity of international firms and trade. 
firms' decision to export or engage in FDI. Mayer and Ottaviano (2007) examined European firms. Regarding Japanese firms, Head and Ries (2003) and Tomiura (2007) have shown that firms' choice of domestic supply, exports, or overseas production through FDI depends on the productivity of firms and only a small number of firms with high productivity engage in FDI. Grossman, Helpman, and Szeidl (2006) expand the model to a threecountry case, and show that firms with higher productivity engage in FDIs in a greater number of countries. Aw and Lee (2008) did a study of Taiwanese firms that empirically demonstrated that there was a difference between the productivity of the firms engaging in FDI in China and the productivity of the firms engaging in FDI in the United States, and that the firms engaging in FDI in both countries were the most productive.

The theoretical framework of Helpman, Melitz, and Yeaple (2004) posits that the characteristics of firms' export markets in which they engage in FDI affect the internationalization mode of firms. Therefore, it is expected that the actual observed modes of internationalization would differ from the standard mode of firms' internationalization, since the productivity-cutoff for overseas production varies according to the country-specific attributes. In fact, Wakasugi et al. (2008), in their empirical studies of Japanese firms that largely produce in Asian countries, show that the disparity between the productivity of the firms implementing exports and those engaging in FDI is smaller than for European firms, and have asserted that factors other than productivity disparity affect the mode of internationalization. We find that Japanese firms of lower productivity actually produce overseas rather than export. One reason for this is that the productivity-cutoff for overseas production varies according to the size of the overseas market, the distance, and the fixed and variable costs in the market. Nevertheless, except for the studies by Chen and Moore (2010) presenting that more productive French firms are more likely than their less efficient competitors to invest in relatively tough host countries and countries with a smaller market potential, higher fixed costs of investment or lower import tariff tend to have higher productivity-cutoff and attract a greater proportion of productive multinationals, few studies have considered that the choice of internationalization depends on countryspecific attributes including the market size, the distance to the market, and fixed and variable costs for export and FDI.

This paper aims to examine what country-specific attributes affect the productivity-cutoff and how they affect the size of overseas production, the number of firms operating overseas production, the average domestic and overseas sales, and the relative size of overseas production to domestic production through the change of productivity-cutoff for overseas production, along with Helpman, Melitz and Yeaple (2004) and Yeaple (2008). The investigation in this paper shows that larger market size and shorter distance between two markets lower the productivity-cutoff for overseas production, and that through varying productivity-cutoff the larger market and the shorter distance positively affect the size of overseas production and the number of firms operating overseas production.

The paper is organized as follows: The next section describes the basic model to determine productivity-cutoff for overseas production. The third section theoretically examines what country-specific attributes determine the productivity-cutoff and empirically tests whether the theoretical prediction is applied to the productivity-cutoff for Japanese multinational firms. The fourth section investigates the impact of country-specific attributes on overseas 
Ryuhei Wakasugi, Ayumu Tanaka: Activities of Japanese Multinationals with Productivity Heterogeneity

production by decomposing it into the number of firms, the average overseas production, the average domestic production, and the relative share of overseas to domestic production, taking into account the effect of varying productivity-cutoff, and empirically tests the theoretical predictions, using the data of Japanese multinationals. Section 5 summarizes the results of the examination in this paper and discusses the remaining issues.

\section{Basic Model}

Helpman, Melitz, and Yeaple (2004) show that under monopolistic competition with given market conditions, firms are heterogeneous in their productivity so that selections by firms of domestic supply, exports, and overseas production vary in accordance with their level of productivity and country-specific attributes, and their production volume and profits are also affected by their productivity and country-specific attributes. In this section, we describe the theoretical framework to examine how market specific factors affect the productivity-cutoff for internationalization, the number of internationalizing firms, the volume of their overseas production, and the average production volume, along with the analytical framework of Helpman, Melitz, and Yeaple (2004).

The consumer's utility function with respect to the differentiated goods in overseas market $j$ is given by the following equation.

$$
U=\left[\int_{l \in D_{j}} x_{j}(l)^{\alpha} d l\right]^{\frac{1}{\alpha}}, \quad 0<\alpha<1
$$

where $x_{j}(l)$ is the consumer's demand for differentiated good $l$ in market $j, D_{j}$ is the set of differentiated goods, $\alpha$ is a parameter to determine the elasticity of substitution between differentiated goods, $\varepsilon=1 /(1-\alpha)$, where we suppose $\varepsilon>1$. The consumer's demand for goods $l$ in the market $j$ is determined as follows.

$$
x_{j}(l)=p_{j}(l)^{-\varepsilon} Y_{j} / P_{j}^{1-\varepsilon}
$$

where $Y_{j}$ is the consumer's expenditure in the overseas market $j, p_{j}(l)$ is the price of goods $l$, and $P_{j}$ is the price index of the market $j$. The budget constraint of the consumer is given by $Y_{j}=\int_{l \in D_{j}} p_{j}(l) x_{j}(l) d l$, and the price index is given by the following equation.

$$
P_{j}=\left[\int_{l \in D_{j}} p_{j}(l)^{1-\varepsilon} d l\right]^{1 /(1-\varepsilon)}
$$

We assume labor to be the only factor input for production. If the labor input to produce one unit of the good is defined by $a$, the productivity of the firm is expressed as $\psi=1 / a$. If the wage rate in the market $j$ is $w_{j}$, the marginal cost for production is expressed as $c_{j}=w_{j} / \psi$. Suppose the cases that the firm produces the good in the domestic market $h$ and exports it to overseas market $j$, and it produces the good in overseas market $j$. We can express the marginal cost for export as $c_{h}=w_{h} \tau_{h} / \psi$. In this case, the wage rate $w_{h}$ is the wage rate in the domestic market $h$, and $\tau_{h}$ is the iceberg type cost necessary for exporting the good from the domestic market to 
the overseas market. It includes the various types of cost necessary for export, including transport cost. Here, we assume that export $\operatorname{cost} \tau_{h}$ is an increasing function of the distance $d$ between two markets-domestic and overseas-as $\tau_{h}{ }^{\prime}(d)>0$.

Since the price of goods at which the firm with productivity $\psi$ supplies the market $j$ is defined by $p_{j}(\psi)=$ $w_{j} /(\alpha \psi)$, the sales volume of the firm $S_{j}$ in the market is expressed as follows:

$$
S_{j}=M_{j} w_{j}^{1-\varepsilon} \psi^{\varepsilon-1}
$$

where $M_{j}=\alpha^{\varepsilon-1} Y_{j} P_{j}^{\varepsilon-1}$.

Equation (4) implies that the higher the productivity of firms, the larger the sales. Suppose the firm that exports finds it necessary to spend the fixed costs for export, $f_{j}^{E}(d)$. Net profit $\pi_{j}^{E}$ of the firm exporting to the overseas market $j$ is written as

$$
\pi_{j}^{E}(\psi)=A_{j}\left(w_{h} \tau_{h}(d)\right)^{1-\varepsilon} \psi^{\varepsilon-1}-f_{j}^{E}(d)
$$

where $A_{j}=(1-\alpha) \alpha^{\varepsilon-1} Y_{j} P_{j}^{\varepsilon-1}$.

Further, we examine the net profit of firms producing in overseas markets. Assume that the firm producing overseas is also required to spend the fixed costs. The net profit of firms producing in overseas market $\pi_{j}^{F}$ is expressed by the following equation:

$$
\pi_{j}^{F}(\psi)=A_{j} w_{j}^{1-\varepsilon} \psi^{\varepsilon-1}-f_{j}^{F}(d)
$$

where $w_{j}$ is the wage rate in the market $j$. Overseas production is carried out only when net profits subtracted by fixed costs are nonnegative.

We assume both fixed costs for export and overseas production increase along with increasing distance. As the distance between markets increases, the firm is required to make more efforts to collect information overseas markets. We can suppose that the fixed costs for export and overseas production increase if the the destination of export and the location of the subsidiary are far from the domestic market. Then, we define the fixed costs as an increasing function of distance expressed by $f_{j}^{E^{\prime}}(d)>0$ and $f_{j}^{F^{\prime}}(d)>0$.

We also assume that $f_{j}^{F}(d)$ is higher than $f_{j}^{E}(d)$ and the marginal increase of fixed costs for overseas production is larger than that for export. Then, $f_{j}^{F}(d)-f_{j}^{E}(d)>0$ and $\left[f_{j}^{F}(d)-f_{j}^{E}(d)\right]^{\prime}>0$.

Firms' choice between export and FDI depends on whether export or FDI brings the higher net profit. From $\tau_{h}{ }^{\prime}(d)>0$, the marginal cost for export increases due to the increased distance between markets. On the other hand, the fixed costs for overseas production become larger than the fixed costs for export if the overseas market is farther away from the domestic market. In other words, fixed costs are higher for overseas production than for exports, whereas the marginal cost for overseas production is lower. Thus, the firm's choice of export or overseas production depends on the distance.

The productivity-cutoff that determines a firm's export or overseas production is defined by the value to equalize 
Ryuhei Wakasugi, Ayumu Tanaka: Activities of Japanese Multinationals with Productivity Heterogeneity

the profits between two internationalization modes, export and overseas production, so that $\pi_{j}^{F}(\psi)=\pi_{j}^{E}(\psi)$.

$$
\text { As we obtain } \quad \hat{\psi}^{\varepsilon-1}=\frac{1}{A_{j}}\left[\frac{f_{j}^{F}(d)-f_{j}^{E}(d)}{w_{j}^{1-\varepsilon}-\left(w_{h} \tau_{h}(d)\right)^{1-\varepsilon}}\right] \quad \text { from equations (5) and (6), the }
$$

productivity-cutoff $\hat{\psi}$ is determined as follows.

$$
\hat{\psi}=\left[\frac{1}{A_{j}}\right]^{\frac{1}{\varepsilon-1}}\left[\frac{f_{j}^{F}(d)-f_{j}^{E}(d)}{w_{j}^{1-\varepsilon}-\left(w_{h} \tau_{h}(d)\right)^{1-\varepsilon}}\right]^{\frac{1}{\varepsilon-1}}
$$

Here we assume that $w_{h} \tau_{h}(d)>w_{j}$.

If the productivity of firm $\psi$ is larger than the cutoff value, $\psi>\hat{\psi}$, then the firm chooses overseas production, and if $\psi<\hat{\psi}$, the firm chooses exports. However, we have to note that the productivity-cutoff $\hat{\psi}$ holds a different value depending on the market size, the disparity between local and overseas wages, export cost, and the distance.

\section{Productivity-cutoff and Country-specific Attributes}

\subsection{Changes of productivity-cutoff}

We examine how the productivity-cutoff $\hat{\psi}$ varies when the size of the market and the distance to the market change.

The effect of increasing market size $Y_{j}$ on the productivity-cutoff is expressed as follows:

$$
\frac{\partial \hat{\psi}}{\partial Y_{j}}=\frac{\partial \hat{\psi}}{\partial A_{j}} \frac{\partial A_{j}}{\partial Y_{j}}<0, \text { since } \frac{\partial \hat{\psi}}{\partial A_{j}}<0 \text { and } \frac{\partial A_{j}}{\partial Y_{j}}>0 .
$$

In other words, an increase in the size of the overseas market lowers the productivity-cutoff $\hat{\psi}$. We can derive the following proposition for the effect of market size on the productivity-cutoff.

Proposition 1. Larger market size lowers the productivity-cutoff for overseas production that firms are required to exceed. Hence, the larger market enables firms with lower productivity to enter into overseas production.

Next, we examine the effect of distance between two markets on the productivity-cutoff. From the first derivative of the productivity-cutoff $\hat{\psi}$ in equation (8) with respect to the distance, we derive,

$$
\begin{array}{r}
\frac{\partial \hat{\psi}^{\varepsilon-1}}{\partial d}=\left(\frac{1}{A_{j}}\right)\left\{\frac{1}{\left[w_{j}{ }^{1-\varepsilon}-\left(w_{h} \tau_{h}(d)\right)^{1-\varepsilon}\right]^{2}}\right\} \\
\cdot\left\{\left[w_{j}{ }^{1-\varepsilon}-\left(w_{h} \tau_{h}(d)\right)^{1-\varepsilon}\right] \frac{\partial}{\partial d}\left[f_{j}^{F}(d)-f_{j}^{E}(d)\right]-\left[f_{j}^{F}(d)-f_{j}^{E}(d)\right] \frac{\partial}{\partial d}\left[w_{j}^{1-\varepsilon}-\left(w_{h} \tau_{h}(d)\right)^{1-\varepsilon}\right]\right\} \\
=\left(\frac{1}{A_{j}}\right)\left\{\frac{1}{\left[w_{j}{ }^{1-\varepsilon}-\left(w_{h} \tau_{h}(d)\right)^{1-\varepsilon}\right]^{2}}\right\} \\
\cdot\left\{\left[f_{j}^{F^{\prime}}(d)-f_{j}^{E^{\prime}}(d)\right]\left[w_{j}^{1-\varepsilon}-\left(w_{h} \tau_{h}(d)\right)^{1-\varepsilon}\right]-\left[(\varepsilon-1) w_{h}^{1-\varepsilon} \tau_{h}(d)^{-\varepsilon} \frac{\partial \tau_{h}(d)}{\partial d}\right]\left[f_{j}^{F}(d)-f_{j}^{E}(d)\right]\right\}
\end{array}
$$

The sign of LHS in equation (9) that depends on the sign of the third term of RHS is not uniquely determined. From $\left[w_{j}^{1-\varepsilon}-\left(w_{h} \tau_{h}(d)\right)^{1-\varepsilon}\right]>0$ and $\left[f_{j}^{F}(d)-f_{j}^{E}(d)\right]>0$, the sign of the third term of RHS depends on the 
relative ratio of the elasticity of fixed costs compared with variable costs. That is,

$$
\begin{array}{ll}
\frac{\partial \hat{\psi}}{\partial d}>0 \\
\text { if } \frac{\partial\left[f_{j}^{F}(d)-f_{j}^{E}(d)\right] /\left[f_{j}^{F}(d)-f_{j}^{E}(d)\right]}{\partial d / d}>\frac{\partial\left[w_{j}{ }^{1-\varepsilon}-\left(w_{h} \tau_{h}(d)\right)^{1-\varepsilon}\right] /\left[w_{j}^{1-\varepsilon}-\left(w_{h} \tau_{h}(d)\right)^{1-\varepsilon}\right]}{\partial d / d}, \\
\text { and } \frac{\partial \hat{\psi}}{\partial d}<0 \\
\text { if } \frac{\partial\left[f_{j}^{F}(d)-f_{j}^{E}(d)\right] /\left[f_{j}^{F}(d)-f_{j}^{E}(d)\right]}{\partial d / d}<\frac{\partial\left[w_{j}{ }^{1-\varepsilon}-\left(w_{h} \tau_{h}(d)\right)^{1-\varepsilon}\right] /\left[w_{j}{ }^{1-\varepsilon}-\left(w_{h} \tau_{h}(d)\right)^{1-\varepsilon}\right]}{\partial d / d}
\end{array}
$$

These inequalities show that if the elasticity of fixed costs with respect to distance is greater than the elasticity of variable export costs with respect to distance, the longer distance raises the productivity-cutoff, and vice versa.

Proposition 2. The impact of increasing distance on the productivity-cutoff for overseas production depends on the elasticity of fixed costs with respect to distance and that of variable costs with respect to distance, which differ according to the market conditions.

(i) If the elasticity of fixed costs with respect to distance is greater than the elasticity of variable costs with respect to distance, only the firms with high productivity can choose overseas production.

(ii) If the elasticity of fixed costs with respect to distance is smaller than the elasticity of variable costs with respect to distance, more firms with lower productivity can choose overseas production.

Whether the elasticity of fixed costs with respect to distance is greater than the elasticity of variable costs depends on the difference in both fixed and variable costs between overseas production and export. The fixed costs for export or overseas production reflect such country-specific attributes as the difficulty to search the partners, the legal institution, and the business practices. We assume that the longer the distance to the destination of export or FDI, the less the firms are acquainted with the country-specific factors. Therefore the distance is thought as a factor to determine the fixed costs. Which is larger, the elasticity of fixed costs or the elasticity of variable costs with respect to distance, can be identified by empirical examination.

\subsection{Determinants of productivity-cutoff}

We investigate the impacts of market size and the distance on changes in productivity-cutoff $\hat{\psi}$, by testing empirically Propositions 1 and 2. For the estimation of the effect of market-specific factors on the productivitycutoff $\hat{\psi}$, we construct the following equation for estimation:

$$
\ln \hat{\psi}_{j}=\alpha_{0}+\alpha_{1} \ln \left(G D P_{j}\right)+\alpha_{2} \ln \left(G D P P C_{j}\right)+\alpha_{3} \ln \left(D I S T A N C E_{j}\right)+\mu_{j}
$$

We estimate equation (10) by using the actually observed productivity-cutoff $\hat{\psi}$ for firms producing in overseas markets as a dependent variable. We deem the statistics of lowest $5 \%$ firms in productivity of producing in overseas markets as the actual productivity-cutoff $\hat{\psi}$. The firm-level data of productivity are calculated from "Basic Survey of Japanese Business Structure and Activities" (1999) of the Ministry of Economy, Trade and Industry. This survey 
Ryuhei Wakasugi, Ayumu Tanaka: Activities of Japanese Multinationals with Productivity Heterogeneity

\begin{tabular}{lccccc}
\hline Variables & Mean & S. D. & N & Min & Max \\
\hline ln FDI sales & 9.487 & 2.441 & 204 & 0.693 & 15.104 \\
In Number of FDI firms & 1.691 & 0.937 & 204 & 0.693 & 4.585 \\
ln Dom. Sales / Number of FDI firms & 11.589 & 1.283 & 204 & 8.876 & 14.340 \\
ln FDI sales / Dom. Sales & -3.793 & 1.781 & 204 & -9.578 & 3.351 \\
ln Average FDI sales & 7.796 & 1.948 & 204 & 0.000 & 12.315 \\
ln TFP & 2.171 & 0.290 & 204 & 1.422 & 2.925 \\
ln Productivity-Cutoff & 9.337 & 1.661 & 204 & 5.970 & 13.519 \\
ln GDP & 26.810 & 1.392 & 204 & 23.277 & 29.874 \\
ln GDPPC & 8.975 & 1.359 & 204 & 5.931 & 10.502 \\
$\ln$ Distance & 8.705 & 0.718 & 204 & 7.053 & 9.781 \\
\hline
\end{tabular}

Table 1 Descriptive Statistics

includes all firms in Japan with 50 or more employees or over 30 million yen of paid capital. ${ }^{2}$ TFP is calculated by the method of Olley and Pakes (1996). ${ }^{3)}$

As for the explanatory variables, we use the GDP of each country $(G D P)$ as a proxy of the size of overseas markets. We add per capita GDP of each country $(G D P P C)$ to control for other country specific factors than the market size and the distance. Both GDP and GDPPC are from the World Bank's World Development Indicators. DISTANC is based on the distance between each overseas market and Japan from the CEPII database. Table 1 shows the descriptive statistics of the data used for estimation.

Based on Propositions 1 and 2, we predict the negative coefficient of the market size as $\alpha_{1}<0$, while we cannot predict the sign of coefficient for the distance because it depends on market specific factors.

Table 2 shows the estimated results. Panel (1) presents the results estimated on country level data and Panel (2) gives the results on country and industry level data ${ }^{4)}$. Coefficients are estimated by feasible generalized least squares.

We find:

(i) the larger market size lowers the productivity-cutoff for firm's overseas production;

(ii) the longer distance raises the productivity-cutoff for overseas production.

The sign of the estimated coefficient for GDP is consistent with the theoretical prediction derived from Propositions 1. From the positive sign of the estimated coefficient for distance, we find that the elasticity of fixed costs with respect to distance is larger than the elasticity of variable costs with respect to distance and therefore find that only the firms with higher productivity can choose overseas production.

2) The finance industry, real estate industry, transportation industry, and communications industry are not included in the survey.

3) Refer to Wakasugi et al (2008) for details.

4) Food products and beverages; Textiles; Wearing apparel; Wood and products of wood; Furniture; Paper and paper products; Publishing and printing; Leather; Rubber products; Chemicals and chemical products; Coke, refined petroleum and plastic products; Other non-metallic mineral products; Basic iron and steel; Non-ferrous metals; Basic metals; Machinery and equipment; Electrical machinery and apparatus; Motor vehicles; and Precision instruments are included in the sample. 


\begin{tabular}{|c|c|c|c|c|}
\hline \multicolumn{5}{|c|}{ (1) Country level data } \\
\hline GDP & $\begin{array}{l}-0.620^{* * *} \\
{[0.165]}\end{array}$ & & & $\begin{array}{l}-0.505^{* * *} \\
{[0.168]}\end{array}$ \\
\hline GDPPC & & $\begin{array}{l}-0.22 \\
{[0.264]}\end{array}$ & & $\begin{array}{l}-0.11 \\
{[0.198]}\end{array}$ \\
\hline Distance & & & $\begin{array}{l}1.942 * * * \\
{[0.435]}\end{array}$ & $\begin{array}{l}1.867 * * * \\
{[0.490]}\end{array}$ \\
\hline Constant & $\begin{array}{l}24.879 * * * \\
{[4.482]}\end{array}$ & $\begin{array}{l}10.745^{* * *} \\
{[2.527]}\end{array}$ & $\begin{array}{l}-8.718^{* * *} \\
{[3.834]}\end{array}$ & $\begin{array}{l}6.033 \\
{[5.372]}\end{array}$ \\
\hline Observations & 38 & 38 & 38 & 38 \\
\hline R-squared & 0.21 & 0.02 & 0.36 & 0.53 \\
\hline \multicolumn{5}{|c|}{ (2) Industry level data } \\
\hline GDP & \begin{tabular}{|l|}
$-0.230^{* * *} *$ \\
{$[0.080]$}
\end{tabular} & & & $\begin{array}{l}-0.423^{* * *} \\
{[0.080]}\end{array}$ \\
\hline GDPPC & & $\begin{array}{l}0.168 * * \\
{[0.084]}\end{array}$ & & $\begin{array}{l}0.184 * * \\
{[0.087]}\end{array}$ \\
\hline Distance & & & $\begin{array}{l}0.743 * * * \\
{[0.151]}\end{array}$ & $\begin{array}{l}0.835^{* * * *} \\
{[0.154]}\end{array}$ \\
\hline Constant & $\begin{array}{l}16.696^{* * * *} \\
{[2.197]}\end{array}$ & $\begin{array}{l}8.945 * * * \\
{[0.889]}\end{array}$ & $\begin{array}{l}4.035 * * * \\
{[1.374]}\end{array}$ & $\begin{array}{l}12.914 * * * \\
{[2.142]}\end{array}$ \\
\hline Observations & 204 & 204 & 204 & 204 \\
\hline R-squared & 0.22 & 0.20 & 0.28 & 0.37 \\
\hline
\end{tabular}

Table 2 Effects of Country-specific Attributes on Productivity-cutoff

\section{Activities of Firms}

\subsection{Effects of country-specific attributes on activities of firms}

The investigation in the previous section shows that productivity-cutoff for exports or FDI varies according to market size and distance between two markets. This means that country-specific attributes affect the activities of firms through the changes in productivity-cutoff. In this section, we examine what country-specific attributes affect the overseas activities of firms.

Here, we decompose the production output of the firm producing in overseas market into the number of firms and the production output of each firm as follows:

$$
S_{j}^{j}=N_{h, j} \times\left(\frac{S_{j}^{j}}{N_{h, j}}\right)
$$

where $S_{j}^{j}$ is the production output of firms producing in overseas market $j, N_{h, j}$ is the number of firms producing in the overseas market, and $S_{j}^{j} / N_{h, j}$ is the average production output of firms producing in the country $j$. The first term is thought of as "extensive margin" and the second term as "intensive margin."

Furthermore, we decompose $S_{j}^{j} / N_{h, j}$ as follows. ${ }^{5)}$

$$
\frac{S_{j}^{j}}{N_{h, j}}=\left(\frac{S_{j}^{h}}{N_{h, j}}\right) \times\left(\frac{S_{j}^{j}}{S_{j}^{h}}\right)
$$

5) We here follow the analytical method by Yeaple (2008). 
Ryuhei Wakasugi, Ayumu Tanaka: Activities of Japanese Multinationals with Productivity Heterogeneity

where $S_{j}^{h}$ is the production output of the firm producing in the domestic market $h$. Then, the first term of the righthand side of equation (12) is the average value of the domestic production of firms possessing overseas subsidiaries and the second term is the relative size of overseas production compared with domestic production.

Here, we assume that the cumulative distribution function of firms with productivity $\psi$ conforms to the Pareto distribution as follows: ${ }^{6}$

$$
G(\psi)=1-\left(\frac{b}{\psi}\right)^{k}, \psi \geq b \geq 0
$$

where $b$ is the lower bound of productivity. By using the cumulative distribution function, we can rewrite the number of firms producing in the overseas market $j\left(N_{h j}\right)$, the overseas production of firms producing in $j$ country's market $\left(S_{j}^{j}\right)$, and the domestic production of firms holding overseas subsidiaries $\left(S_{j}^{h}\right)$, respectively, as follows:

$$
\begin{aligned}
N_{h, j} & =N_{h}(1-G(\hat{\psi}))=N_{h} b^{k} \hat{\psi}^{-k} \\
S_{j}^{j} & =A_{j} w_{j}{ }^{1-\varepsilon} N_{h} \int_{\hat{\psi}}^{\infty} \psi^{\varepsilon-1} d G(\psi)=A_{j} w_{j}{ }^{1-\varepsilon} N_{h} k b^{k} \frac{1}{k-(\varepsilon-1)} \hat{\psi}^{-(k-(\varepsilon-1))} \\
& =w_{j}{ }^{1-\varepsilon} N_{h} k b^{k}\left[\frac{1}{k-(\varepsilon-1)}\right]\left[\frac{f_{j}^{F}(d)-f_{j}^{E}(d)}{w_{j}{ }^{1-\varepsilon}-\left(w_{h} \tau_{h}(d)\right)^{1-\varepsilon}}\right]^{-\frac{k-(\varepsilon-1)}{\varepsilon-1}} A_{j}^{\frac{k}{\varepsilon-1}} \\
S_{j}^{h} & =A_{h} w_{h}{ }^{1-\varepsilon} N_{h} \int_{\hat{\psi}}^{\infty} \psi^{\varepsilon-1} d G(\psi)=A_{h} w_{h}{ }^{1-\varepsilon} N_{h} k b^{k} \frac{1}{k-(\varepsilon-1)} \hat{\psi}^{-(k-(\varepsilon-1))} \\
& =A_{h} w_{h}{ }^{1-\varepsilon} N_{h} k b^{k}\left[\frac{1}{k-(\varepsilon-1)}\right]\left[\frac{f_{j}^{F}(d)-f_{j}^{E}(d)}{w_{j}{ }^{1-\varepsilon}-\left(w_{h} \tau_{h}(d)\right)^{1-\varepsilon}}\right]^{-\frac{k-(\varepsilon-1)}{\varepsilon-1}} A_{j}{ }^{\left(\frac{k}{\varepsilon-1}-1\right)}
\end{aligned}
$$

where $N_{h}$ is the total number of firms producing in the domestic market.

The choice of overseas production is determined by the firm's productivity and the productivity-cutoff $\hat{\psi}$ in equation (7) since the productivity-cutoff varies according to the changes of the size of overseas market and the distance between two markets as Propositions 1 and 2 show.

$$
\begin{gathered}
\frac{S_{j}^{j}}{N_{h, j}}, \frac{S_{j}^{h}}{N_{h, j}} \text { and } \frac{S_{j}^{j}}{S_{j}^{h}} \quad \text { are rewritten by substituting equations (13)-(15). } \\
\frac{S_{j}^{j}}{N_{h, j}}=\frac{A_{j} w_{j}^{1-\varepsilon}}{k-(\varepsilon-1)} k \hat{\psi}^{\varepsilon-1}=\left[\frac{k}{k-(\varepsilon-1)}\right]\left[\frac{f_{j}^{F}(d)-f_{j}^{E}(d)}{1-\left[\left(w_{h} \tau_{h}\right) / w_{j}\right]^{1-\varepsilon}}\right] \\
\frac{S_{j}^{h}}{N_{h, j}}=\frac{A_{h} w_{h}^{1-\varepsilon}}{k-(\varepsilon-1)} k \hat{\psi}^{\varepsilon-1}=\left(\frac{A_{h}}{A_{j}}\right) \frac{k w_{h}^{1-\varepsilon}}{(k-(\varepsilon-1))}\left[\frac{f_{j}^{F}(d)-f_{j}^{E}(d)}{w_{j}^{1-\varepsilon}-\left(w_{h} \tau_{h}\right)^{1-\varepsilon}}\right]
\end{gathered}
$$

6) The variance of productivity is given by the following equation: $V(\psi)=\frac{b^{2} k}{(k-1)(k-2)}$ As $k$ gets smaller, the variance gets larger. For the variance of drawn productivity to be finite, it must be that $k>2$. 


$$
\frac{S_{j}^{j}}{S_{j}^{h}}=\frac{A_{j}}{A_{h}}\left[\frac{w_{j}}{w_{h}}\right]^{1-\varepsilon}
$$

The activities of multinational firms expressed by equations (13) - (18) vary with changes in the size of the markets, wage, the fixed costs and the export cost due to the distance between two markets.

At first, we investigate the impact of market size on the overseas production, the number of firms, the average sales of domestic and overseas production, and the relative size of overseas production compared with domestic production. Hereinafter, we assume $k-(\varepsilon-1)>0$. By taking the first derivative of equations (13)—(18) with respect to market size $Y_{j}$, we derive

$$
\begin{aligned}
& \frac{\partial S_{j}^{j}}{\partial Y_{j}}=\frac{\partial S_{j}^{j}}{\partial A_{j}} \frac{\stackrel{(+)}{\partial A_{j}}}{\partial Y_{j}}>0, \frac{\partial N_{h j}}{\partial Y_{j}}=\frac{\partial{\stackrel{(-)}{N_{h, j}}}}{\partial \hat{\psi}} \frac{(-)}{\partial \hat{\psi}_{j}}>0, \frac{\partial S_{j}^{j} / N_{h, j}}{\partial Y_{j}}=0 \\
& \frac{\partial\left(S_{j}^{h} / N_{h, j}\right)}{\partial Y_{j}}=\frac{\partial\left(S_{j}^{h} / N_{h, j}\right)}{\partial \hat{\psi}} \frac{\stackrel{(-)}{\partial \hat{\psi}}}{\partial A_{j}} \frac{{ }_{(+)}}{\partial Y_{j}}<0 \text { since } \frac{\partial\left(S_{j}^{h} / N_{h, j}\right)}{\partial \hat{\psi}}>0 \text {, and } \\
& \frac{\partial\left(S_{j}^{j} / S_{j}^{h}\right)}{\partial Y_{j}}=\frac{\partial\left(S_{j}^{j} / S_{j}^{h}\right)}{\partial A_{j}} \frac{\stackrel{(+)}{\partial A_{j}}}{\partial Y_{j}}>0
\end{aligned}
$$

From the above, we derive the following Proposition.

\section{Proposition 3.}

The expansion of the size of the overseas market

(i) increases the overseas production;

(ii) increases the number of firms producing in the overseas market, but

(iii) does not change the average value of overseas production;

(iv) lowers the average domestic production of firms producing in that market;

(v) raises the relative share of overseas production to domestic production.

Next, we examine the impact of the distance on overseas production, the number of firms, the average sales of domestic and overseas production, and the relative size of overseas production compared with domestic production. We take the first derivative of equations (13)—(18) with respect to the distance as follows:

$$
\begin{gathered}
\frac{\partial\left(S_{j}^{j} / S_{j}^{h}\right)}{\partial d}=0 \\
\frac{\partial S_{j}^{j}}{\partial d}=\frac{\partial S_{j}^{j}}{\partial \hat{\psi}} \frac{\partial \hat{\psi}}{\partial d}
\end{gathered}
$$




$$
\begin{aligned}
& \frac{\partial N_{h j}}{\partial d}=\frac{\partial N_{h, j}}{\partial \hat{\psi}} \frac{\partial \hat{\psi}}{\partial d} \\
& \frac{\partial\left(S_{j}^{j} / N_{h, j}\right)}{\partial d}=\frac{\partial\left\{\left[\left(A_{j} w_{j}^{1-\varepsilon} k\right) /(k-(\varepsilon-1))\right] \hat{\psi}^{\varepsilon-1}\right\}}{\partial d}=\frac{A_{j} w_{j}^{1-\varepsilon} k(\varepsilon-1)}{k-(\varepsilon-1)} \hat{\psi}^{\varepsilon-2} \frac{\partial \hat{\psi}}{\partial d} \\
& \frac{\partial\left(S_{j}^{h} / N_{h, j}\right)}{\partial d}=\frac{\partial\left\{\left[\left(A_{h} w_{h}^{1-\varepsilon} k\right) /(k-(\varepsilon-1))\right] \hat{\psi}^{\varepsilon-1}\right\}}{\partial d}=\frac{A_{h} w_{h}^{1-\varepsilon} k(\varepsilon-1)}{k-(\varepsilon-1)} \hat{\psi}^{\varepsilon-2} \frac{\partial \hat{\psi}}{\partial d}
\end{aligned}
$$

From the above, we find that the impacts of distance on the size of overseas production, the number of firms producing in overseas markets, and the average domestic and overseas production depend on the effect of different distance on productivity-cutoff. The results of empirical examination in the previous section show that the longer distance raises the productivity-cutoff for Japanese firm's overseas production, that is $\frac{\partial \hat{\psi}}{\partial d}>0$. Based on the results, we predict the sign of the first derivatives of equations (13), (14), (16), and (17) with respect to the distance as follows:

$$
\frac{\partial S_{j}^{j}}{\partial d}<0, \frac{\partial N_{h j}}{\partial d}<0, \frac{\partial\left(S_{j}^{j} / N_{h, j}\right)}{\partial d}>0, \frac{\partial\left(S_{j}^{h} / N_{h, j}\right)}{\partial d}>0
$$

\section{Proposition 4.}

The longer distance between domestic and overseas markets

(i) does not affect the relative size of overseas production compared with domestic production at all;

(ii) reduces the size of overseas production

(iii) reduces the number of firms producing in overseas markets, but

(iv) raises the average domestic production and the average overseas production

\subsection{Empirical tests}

We statistically investigate whether Propositions 3 and 4 are applied to explain the activities of Japanese firms. For estimating the sign of the market size and the distance, we use GDP of each country as a proxy of the size of overseas markets and the distance between overseas market and Japan. We add per capita GDP of each country to control for other country specific factors than the size and the distance. The equation for empirical estimation is expressed as follows:

$$
\ln Z_{n}^{j}=\beta_{0}+\beta_{1} \ln \left(G D P_{j}\right)+\beta_{2} \ln \left(G D P P C_{j}\right)+\beta_{3} \ln \left(D I S T A N C E_{j}\right)+\mu_{j}
$$

Here $Z_{n}^{j}=S_{j}^{j}, N_{h, j}, \frac{S_{j}^{j}}{N_{h, j}}, \frac{S_{h}^{j}}{N_{h, j}}$, and $\frac{S_{j}^{j}}{S_{h}^{j}}$.

Given the estimated coefficient for the effect of distance on productivity-cutoff is positive, we predict the sign of coefficients for the effects of market size and distance on FDI sales, the number of firms, average domestic production, average overseas production, and the ratio of overseas production to domestic production as tabulated 
in Table 3.

\begin{tabular}{lccccc}
\hline & Sales & $\begin{array}{c}\text { Number of } \\
\text { Firms }\end{array}$ & $\begin{array}{c}\text { Average } \\
\text { Overseas Sales }\end{array}$ & $\begin{array}{c}\text { Average } \\
\text { Domestic } \\
\text { Sales }\end{array}$ & $\begin{array}{c}\text { Overseas / } \\
\text { Domestic } \\
\text { Sales }\end{array}$ \\
\hline GDP & $(+)$ & $(+)$ & 0 & $(-)$ & $(+)$ \\
Distance & $(-)$ & $(-)$ & $(+)$ & $(+)$ & 0 \\
\hline
\end{tabular}

Table 3 Predicted Sign

\begin{tabular}{|c|c|c|c|c|}
\hline \multirow[b]{2}{*}{$\overline{\text { GDP }}$} & \multicolumn{4}{|c|}{ (1) FDI sales } \\
\hline & $\begin{array}{l}1.083 * * * \\
{[0.238]}\end{array}$ & & & $\begin{array}{l}0.886^{* * *} \\
{[0.261]}\end{array}$ \\
\hline GDPPC & & $\begin{array}{l}0.665^{* *} \\
{[0.304]}\end{array}$ & & $\begin{array}{l}0.34 \\
{[0.225]}\end{array}$ \\
\hline Distance & & & $\begin{array}{l}-1.639 * * * \\
{[0.529]}\end{array}$ & $\begin{array}{l}-1.560^{* * *} \\
{[0.383]}\end{array}$ \\
\hline Constant & $\begin{array}{l}-17.029^{* * *} \\
{[6.151]}\end{array}$ & $\begin{array}{l}5.130^{*} \\
{[2.684]}\end{array}$ & $\begin{array}{l}25.834^{* * * *} \\
{[4.606]}\end{array}$ & $\begin{array}{l}-0.917 \\
{[7.417]}\end{array}$ \\
\hline \multirow[t]{2}{*}{$\underline{\mathrm{R} \text {-squared }}$} & 0.33 & 0.10 & 0.13 & 0.45 \\
\hline & \multicolumn{4}{|c|}{ (1) Number of FDI firms } \\
\hline$\overline{\text { GDP }}$ & \begin{tabular}{|l}
$\mid 0.702^{* * *}$ \\
{$[0.131]$}
\end{tabular} & & & $\begin{array}{l}0.705^{* * *} \\
{[0.148]}\end{array}$ \\
\hline GDPPC & & $\begin{array}{l}0.134 \\
{[0.213]}\end{array}$ & & $\begin{array}{l}-0.124 \\
{[0.126]}\end{array}$ \\
\hline Distance & & & $\begin{array}{l}-1.444 * * * \\
{[0.293]}\end{array}$ & $\begin{array}{l}-1.238^{* * * *} \\
{[0.259]}\end{array}$ \\
\hline Constant & $\mid \begin{array}{l}-15.437 * * * \\
{[3.352]}\end{array}$ & $\begin{array}{l}1.596 \\
{[1.919]}\end{array}$ & $\begin{array}{l}15.797^{* * * *} \\
{[2.539]}\end{array}$ & $\begin{array}{l}-3.232 \\
{[4.756]}\end{array}$ \\
\hline \multirow[t]{2}{*}{$\underline{\mathrm{R} \text {-squared }}$} & 0.38 & 0.01 & 0.27 & 0.60 \\
\hline & \multicolumn{4}{|c|}{ (3) Average FDI sales } \\
\hline$\overline{\text { GDP }}$ & $\begin{array}{l}0.380^{* *} \\
{[0.153]}\end{array}$ & & & $\begin{array}{l}0.182 \\
{[0.173]}\end{array}$ \\
\hline GDPPC & & $\begin{array}{l}0.531^{* * *} \\
{[0.177]}\end{array}$ & & $\begin{array}{l}0.464^{* *} \\
{[0.204]}\end{array}$ \\
\hline Distance & & & $\begin{array}{l}-0.196 \\
{[0.361]}\end{array}$ & $\begin{array}{l}-0.322 \\
{[0.298]}\end{array}$ \\
\hline Constant & $\mid \begin{array}{l}-1.592 \\
{[4.008]}\end{array}$ & $\begin{array}{l}3.534^{* *} \\
{[1.542]}\end{array}$ & $\begin{array}{l}10.037^{* * *} \\
{[3.200]}\end{array}$ & $\begin{array}{l}2.315 \\
{[4.587]}\end{array}$ \\
\hline \multirow[t]{2}{*}{ R-squared } & 0.11 & 0.17 & 0.01 & 0.21 \\
\hline & \multicolumn{4}{|c|}{ (4) Average Domestic sales } \\
\hline$\overline{\text { GDP }}$ & \begin{tabular}{|l|}
$-0.213^{* *}$ \\
{$[0.092]$}
\end{tabular} & & & $\begin{array}{l}-0.197^{*} \\
{[0.104]}\end{array}$ \\
\hline GDPPC & & $\begin{array}{l}-0.023 \\
{[0.154]}\end{array}$ & & $\begin{array}{l}0.024 \\
{[0.162]}\end{array}$ \\
\hline Distance & & & $\begin{array}{l}0.731 * * * \\
{[0.240]}\end{array}$ & $\begin{array}{l}0.678^{* *} \\
{[0.257]}\end{array}$ \\
\hline Constant & $\begin{array}{l}17.831^{* * *} \\
{[2.434]}\end{array}$ & $\begin{array}{l}12.500^{* * *} \\
{[1.381]}\end{array}$ & $\begin{array}{l}5.708^{* *} \\
{[2.157]}\end{array}$ & $\begin{array}{l}11.086^{* * *} \\
{[3.127]}\end{array}$ \\
\hline \multirow[t]{2}{*}{$\underline{\mathrm{R} \text {-squared }}$} & 0.08 & 0.00 & 0.15 & 0.21 \\
\hline & \multicolumn{4}{|c|}{0.00 (5) FDI sales/Domestic sales } \\
\hline$\overline{\text { GDP }}$ & \begin{tabular}{|l}
$0.594 * * *$ \\
{$[0.166]$}
\end{tabular} & & & $\begin{array}{l}0.379 * * \\
{[0.173]}\end{array}$ \\
\hline GDPPC & & $\begin{array}{l}0.554 * * * \\
{[0.174]}\end{array}$ & & $\begin{array}{l}0.441 * * * \\
{[0.156]}\end{array}$ \\
\hline Distance & & & $\begin{array}{l}-0.926^{* * *} \\
{[0.336]}\end{array}$ & $\begin{array}{l}-1.000^{* * *} \\
{[0.299]}\end{array}$ \\
\hline Constant & $\begin{array}{l}-19.423 * * * \\
{[4.410]}\end{array}$ & $\begin{array}{l}-8.966 * * * \\
{[1.627]}\end{array}$ & $\begin{array}{l}4.33 \\
{[2.882]}\end{array}$ & $\begin{array}{l}-8.771^{* *} \\
{[4.273]}\end{array}$ \\
\hline $\mathrm{R}$-squared & 0.26 & 0.18 & 0.11 & 0.43 \\
\hline Observations & 38 & 38 & 38 & 38 \\
\hline
\end{tabular}

Table 4 Effects of Country-specific Attributes on Activities of Multinational Firms: by Country

\begin{tabular}{|c|c|c|c|c|}
\hline & \multicolumn{4}{|c|}{ (1) FDI sales } \\
\hline$\overline{\text { GDP }}$ & $\begin{array}{l}0.835^{* * * *} \\
{[0.099]}\end{array}$ & & & $\begin{array}{l}.794^{* * * *} \\
{[0.105]}\end{array}$ \\
\hline GDPPC & & $\begin{array}{l}0.563 * * * \\
0.113]\end{array}$ & & $\begin{array}{l}0.386^{* * *} \\
{[0.113]}\end{array}$ \\
\hline Distance & & & $\begin{array}{l}-0.141 \\
{[0.228]}\end{array}$ & $\begin{array}{l}-0.849^{* * *} \\
{[0.202]}\end{array}$ \\
\hline Constant & $\begin{array}{l}-13.039^{* * *} \\
{[2.721]}\end{array}$ & $\begin{array}{l}4.195 * * * \\
{[1.203]}\end{array}$ & $\begin{array}{l}10.638^{* * * *} \\
{[2.082]}\end{array}$ & $\begin{array}{l}-8.135 * * * \\
{[2.797]}\end{array}$ \\
\hline \multirow[t]{2}{*}{ R-squared } & 0.45 & 0.32 & 0.23 & 0.51 \\
\hline & \multicolumn{4}{|c|}{ (2) Number of FDI firms } \\
\hline GDP & $\begin{array}{l}0.366^{* * * *} \\
{[0.036]}\end{array}$ & & & $\begin{array}{l}0.434^{* * * *} \\
{[0.037]}\end{array}$ \\
\hline GDPPC & & $\begin{array}{l}0.081^{*} \\
{[0.046]}\end{array}$ & & $\begin{array}{l}-0.029 \\
{[0.040]}\end{array}$ \\
\hline Distance & & & $\begin{array}{l}-0.188^{* * *} \\
{[0.087]}\end{array}$ & $\begin{array}{l}-0.399^{* * *} \\
{[0.071]}\end{array}$ \\
\hline Constant & $\begin{array}{l}-8.308^{* * * *} \\
{[0.995]}\end{array}$ & $\begin{array}{l}0.782 \\
{[0.492]}\end{array}$ & $\begin{array}{l}3.165 * * * \\
{[0.797]}\end{array}$ & $\begin{array}{l}-6.393^{* * * *} \\
{[0.985]}\end{array}$ \\
\hline \multirow[t]{2}{*}{ R-squared } & 0.50 & 0.23 & 0.24 & 0.58 \\
\hline & \multicolumn{4}{|c|}{ (3) Average FDI sales } \\
\hline GDP & $\begin{array}{l}0.469^{* * * *} \\
{[0.090]}\end{array}$ & & & $\begin{array}{l}0.361^{* * * *} \\
{[0.096}\end{array}$ \\
\hline GDPPC & & $\begin{array}{l}0.482^{* * * *} \\
{[0.093]}\end{array}$ & & $\begin{array}{l}0.415^{* * * *} \\
{[0.104]}\end{array}$ \\
\hline Distance & & & $\begin{array}{l}0.047 \\
{[0.188]}\end{array}$ & $\begin{array}{l}-0.450^{* *} \\
{[0.185]}\end{array}$ \\
\hline Constant & $\begin{array}{l}-4.731^{*} \\
{[2.463]}\end{array}$ & $\begin{array}{l}3.413 * * * \\
{[0.986]}\end{array}$ & $\begin{array}{l}7.473 * * * \\
{[1.718]}\end{array}$ & $\begin{array}{l}-1.742 \\
{[2.563]}\end{array}$ \\
\hline \multirow[t]{2}{*}{ R-squared } & 0.29 & 0.29 & 0.18 & 0.35 \\
\hline & \multicolumn{4}{|c|}{ (4) Average Domestic sales } \\
\hline$\overline{\text { GDP }}$ & $\begin{array}{l}0.132^{* *} \\
{[0.057]}\end{array}$ & & & $\begin{array}{l}0.038 \\
{[0.062]}\end{array}$ \\
\hline GDPPC & & $\begin{array}{l}0.215^{* * * *} \\
{[0.058]}\end{array}$ & & $\begin{array}{l}0.153^{* *} \\
{[0.067]}\end{array}$ \\
\hline Distance & & & $\begin{array}{l}0.352 * * * \\
{[0.111]}\end{array}$ & $\begin{array}{l}0.219^{*} \\
{[0.119]}\end{array}$ \\
\hline Constant & $\begin{array}{l}9.138^{* * *} \\
{[1.567]}\end{array}$ & $\begin{array}{l}10.707 * * * \\
{[0.613]}\end{array}$ & $\begin{array}{l}9.637 * * * \\
{[1.007]}\end{array}$ & $\begin{array}{l}8.339^{* * * *} \\
{[1.652]}\end{array}$ \\
\hline \multirow[t]{2}{*}{ R-squared } & 0.33 & 0.36 & 0.35 & 0.38 \\
\hline & \multicolumn{4}{|c|}{ (5) FDI sales/Domestic sales } \\
\hline GDP & $\begin{array}{l}0.337^{* * * *} \\
{[0.085]}\end{array}$ & & & $\begin{array}{l}.322^{* * * *} \\
{[0.091]}\end{array}$ \\
\hline GDPPC & & $\begin{array}{l}0.268^{* * * *} \\
{[0.089]}\end{array}$ & & $\begin{array}{l}0.262^{* * *} \\
{[0.098]}\end{array}$ \\
\hline Distance & & & $\begin{array}{l}-0.305^{*} \\
{[0.172]}\end{array}$ & $\begin{array}{l}-0.669^{* * *} \\
{[0.175]}\end{array}$ \\
\hline Constant & {$[2.329]$} & $\begin{array}{l}-7.294 * * * \\
{[0.948]}\end{array}$ & $\begin{array}{l}-2.164 \\
{[1.566]}\end{array}$ & $\begin{array}{l}-10.081 * * * \\
{[2.427]}\end{array}$ \\
\hline$\underline{R \text {-squared }}$ & 0.24 & 0.21 & 0.19 & 0.30 \\
\hline Observations & 204 & 204 & 204 & 204 \\
\hline
\end{tabular}

Table 5 Effects of Country-specific Attributes on Activities of Multinational Firms: by Country and Industry

Here, we describe the source of data used for estimation. For the dependent variables, the data for overseas production, the number of firms producing in overseas markets, the average value of domestic production per firm producing in overseas markets, the average value of overseas production per firm, and the ratio of overseas to domestic production are calculated from "Basic Survey of Japanese Business Structure and Activities" (1999) and "Survey of Overseas Business Activities" (1999) by the Ministry of Economy, Trade and Industry. From the limited availability of firm-level data, we use the sales of Japanese foreign affiliates as the size of their overseas 
Ryuhei Wakasugi, Ayumu Tanaka: Activities of Japanese Multinationals with Productivity Heterogeneity

productions. As for the explanatory variables, each country's GDP and per capita GDP (GDPPC) are from the World Bank's World Development Indicators, and the distance (DISTANCE) between destination country and Japan is from the CEPII database. Table 1 tabulates the descriptive statistics of these data.

We conduct two estimations: one is based on country data and the other is based on country and industry data by controlling for the industry characteristics through the introduction of industry dummy variables. The purpose of the latter is to increase the sample size. Table 4 presents the results estimated by country data, and Table 5 shows the results by country and industry data. We find that the two results are similar.

Panel (1) in Table 4 and Panel (1) in Table 5 show the effects of market size and distance on the sales of overseas subsidiaries. We find that the sales of overseas subsidiaries rise according to the increase of GDP and fall according to the increase of distance. These results are consistent with the theoretical prediction.

Panel (2) in Table 4 and Panel (2) in Table 5 show the effects of market size and distance on the number of FDI firms, We find that the number of firms operating overseas production increases according to the increase of GDP and decreases according to the increased distance. These results are all consistent with the theoretical prediction.

Panel (3) in Table 4 and Panel (3) in Table 5 show the effects of market size and distance on the average sales of overseas subsidiaries. As for the effects of market size, the estimated results in Table 4 and Table 5 are positive or statistically insignificant. As for the effects of distance, the results in Table 4 and Table 5 are negative or statistically insignificant. The positive sign for GDP and the negative sign for distance are not consistent with the theoretical prediction.

Panel (4) in Table 4 and Panel (4) in Table 5 show the effects of market size and distance on the average domestic sales of firms operating overseas production. We find that the average domestic sales decrease according to an increase of GDP and are positively affected by the increase in distance, except for the insignificantly estimated results of the effect of market size based on the country and industry data. These are almost consistent with the theoretical prediction.

Panel (5) in Table 4 and Panel (5) in Table 5 show the effects of market size and distance on the relative size of overseas production compared with domestic production. We find that the effect of increasing market size affects positively the relative size of overseas to domestic production with a statistical significance in both Table 4 and Table 5, while the effect of increasing distance affects negatively the relative size of overseas production compared with domestic production. These are contradictory to the theoretical prediction.

In summary, we find that the results of the empirical estimation of the impacts of market size and distance on overseas production, the number of firms and the average domestic production support the theoretical proposition, while we find that the impacts of market size on the average overseas production and the impacts of distance on the average overseas production and the relative size of overseas production compared with domestic production are partly inconsistent with the theoretical prediction. Yeaple (2008), by using US firm data, estimated the impact of distance on overseas production, the number of firms, and the average overseas production. The results of our analysis based on Japanese firm-level data are almost consistent with the results of Yeaple (2008). 


\subsection{Other costs}

The difference in wage rate among countries is also a factor to affect the productivity-cutoff and the activities of multinational firms in overseas market. In equation (7) the wage rate in overseas market $w_{j}$ affects the productivitycutoff. We easily find that higher wage rate in the overseas market raises the productivity-cutoff and only the firms with higher productivity enter into overseas market in which the wage is high $^{7)}$. We also theoretically predict that a rise of wage rate in overseas markets reduces the size of overseas production, the number of firms producing in the overseas market and the relative share of overseas production to domestic production, but raises both the average domestic production and the average overseas production $^{8)}$. In this paper we do not conduct empirical estimation to test whether these theoretical predictions are applied to Japanese firms, because of the limitation of availability of wage data by country and industry. Instead, in our estimation we included per capita GDP to control for country-specific variables which may reflect the difference in wage. We note that the estimated coefficients of per capita GDP on the number of firms, the average domestic production and the average overseas production are consistent with theoretical prediction for the effects of wage.

\section{Conclusion}

This paper aimed to investigate what country-specific attributes affect the productivity-cutoff and how these factors affect, through varying productivity-cutoff, the size of overseas production, the number of firms, the average domestic and overseas sales, and their relative ratio, along with Helpman, Melitz, and Yeaple (2004) and Yeaple (2008). The results of theoretical and empirical studies in this paper show that larger market size lowers the productivity-cutoff for overseas production, and longer distance to overseas market raises it. The paper also examines the effect of changes in market size and distance on firm's activities in overseas market: overseas production, the number of FDI firms, the average domestic and overseas production, and their relative ratio. After taking into account the effect of varying productivity-cutoff, the results of empirical tests present that the larger market and the shorter distance positively affect the size of overseas production and increase the number of firms operating overseas production. They are consistent with the theoretical prediction. Nevertheless, we note that the effects of larger market size and longer distance on the average overseas sales and the relative share of overseas

7) The first derivative of the productivity-cutoff $\hat{\psi}$ with respect to the wage change indicates the effect of wage as follows: $\frac{\partial \hat{\psi}}{\partial w_{j}}=\left[\frac{1}{A_{j}}\right]^{\frac{1}{\varepsilon-1}}\left[\frac{f_{j}^{F}(d)-f_{j}^{E}(d)}{\left\{w_{j}^{1-\varepsilon}-\left(w_{h} \tau_{h}\right)^{1-\varepsilon}\right\}^{\varepsilon}}\right]^{\frac{1}{\varepsilon-1}} w_{j}^{-\varepsilon}>0$

8) By taking the first derivative of equations (13), (14), (16) - (18), we find the results as follows:

$$
\begin{aligned}
& \frac{\partial S_{j}^{j}}{\partial w_{j}}=A_{j} w_{j}^{-\varepsilon} N_{h} k b^{k} \hat{\psi}^{-(k-(\varepsilon-1))}\left[\frac{(1-\varepsilon)}{k-(\varepsilon-1)}-\frac{w_{j}}{\hat{\psi}} \frac{\partial \hat{\psi}}{\partial w_{j}}\right]<0, \frac{\partial N_{h, j}}{\partial w_{j}}=-k N_{h} b^{k} \hat{\psi}^{-k-1} \frac{\partial \hat{\psi}}{\partial w_{j}}<0, \frac{\partial\left(S_{j}^{j} / N_{h, j}\right)}{\partial w_{j}}= \\
& {\left[\frac{k}{k-(\varepsilon-1)}\right]\left[f_{j}^{F}(d)-f_{j}^{E}(d)\right]\left(1-\left[w_{j} /\left(w_{h} \tau_{h}\right)\right]^{\varepsilon-1}\right)^{-2}\left[\frac{w_{j}^{\varepsilon-2}}{\left(w_{h} \tau_{h}\right)^{\varepsilon-1}}\right]>0, \frac{\partial\left(S_{j}^{h} / N_{h, j}\right)}{\partial w_{j}}=\frac{A_{h} w_{h}^{1-\varepsilon}}{k-(\varepsilon-1)} k(\varepsilon-1) \hat{\psi}^{\varepsilon-2} \frac{\partial \hat{\psi}}{\partial w_{j}}>0 \text { and } \frac{\partial\left(S_{j}^{j} / S_{j}^{h}\right)}{\partial w_{j}}=} \\
& (1-\varepsilon) \frac{A_{j}}{A_{h}}\left[\frac{1}{w_{h}}\right]^{1-\varepsilon} w_{j}^{-\varepsilon}<0
\end{aligned}
$$


Ryuhei Wakasugi, Ayumu Tanaka: Activities of Japanese Multinationals with Productivity Heterogeneity

production to domestic production are contradictory to the theoretical prediction in some cases. This might be caused by the estimation method of this paper which is based on the pooled data by country and industry in 1999, not based on the panel data because of the limitation of data availability. Other country-specific attributes including the wage, institutional factors and the matching opportunity to meet good partners for investment also must be taken into account to identify country-specific factors.

\section{References}

[ 1 ] Aw, Bee Yan and Yi Lee (2008), "Firm Heterogeneity and Location Choice of Taiwanese Multinationals," Journal of International Economics 76(2): 403-415.

[ 2 ] Chen, Maggie Xiaoyang and Michael O. Moore (2010), "Location Decision of Heterogeneous Multinational Firms," Journal of International Economics, 80(2): 188-199.

[ 3 ] Grossman, Gene, Elhanan Helpman, Adam Szeidl (2006), "Optimal Integration Strategies for the Multinational Firm," Journal of International Economics 70(1): 216-238.

[ 4 ] Head, Keith, and John Ries (2003), "Heterogeneity and the FDI versus Exports Decision of Japanese Manufacturers," Journal of the Japanese and International Economies 17(4): 448-467.

[ 5 ] Helpman, Elhanan, Marc Melitz, and Yona Rubinstein (2008), “Trading Partners and Trading Volumes," Quarterly Journal of Economics 123(2): 441-487.

[6] Helpman, Elhanan, Marc Melitz, and Stephen Yeaple (2004), "Exports versus FDI with Heterogeneous Firms," American Economic Review 94(1): 300-316.

[ 7 ] Mayer, Thierry and Gianmarco I.P. Ottaviano (2007), The Happy Few: The Internationalisation of European Firms. Bruegel Blueprint Series.

[ 8 ] Melitz, Marc (2003), "The Impact of Trade on Intra-Industry Reallocations and Aggregate Industry Productivity," Econometrica 71: 1695-1725.

[ 9 ] Olley, G. Steven and Ariel Pakes (1996), "The Dynamics of Productivity in the Telecommunications Equipment Industry," Econometrica, 64(6): 1263-1297.

[10] Tomiura, Eiichi (2007), "Foreign Outsourcing, Exporting, and FDI: A Productivity Comparison at the Firm Level," Journal of International Economics 72(1): 113-127.

[11] Wakasugi, Ryuhei, Yasuyuki Todo, Hitoshi Sato, Shuichiro Nishioka, Toshiyuki Matsuura, Banri Ito, and Ayumu Tanaka (2008), "The Internationalization of Japanese Firms: New Findings Based on Firm-Level Data," RIETI Discussion Paper, No. 08-E-036, October.

[12] Yeaple, Stephen Ross (2009), "Firm Heterogeneity and the Structure of U.S. Multinational Activity," Journal of International Economics, 78 (2): 206-215. 